\title{
Biodegradation of oil-based paint by Bacillus species monocultures isolated from the paint warehouses
}

\author{
A. H. Phulpoto ${ }^{1}$ M. A. Qazi ${ }^{1,2} \cdot$ S. Mangi ${ }^{1}$ S. Ahmed ${ }^{2}$ N. A. Kanhar'
}

Received: 9 January 2015/Revised: 5 May 2015 / Accepted: 5 July 2015/Published online: 22 July 2015

(C) Islamic Azad University (IAU) 2015

\begin{abstract}
Environmental pollution by oil-based paint effluents is of great concern nowadays due to widespread applications of oil-based paints that cause discharge and accidental spillages into the environment. The present study sought to explore the potential use of indigenous bacterial isolates for biodegradation of oil-based paints. The oil-based-paint-biodegrading potential of three Bacillus species isolated from paint-polluted soil samples of different paint warehouses was investigated by the enumeration, screening and taxonomic characterization of oilbased-paint-degrading bacteria using soil enrichment technique in mineral salt medium (MSM). The screened isolates were identified based on morphological, biochemical and 16S rRNA gene sequence homology methods. The bioremediation potential of each bacterial isolate was determined for a period of 14 days at $37{ }^{\circ} \mathrm{C}$ and $160 \mathrm{rpm}$ in 250-ml shake flask containing $100 \mathrm{ml}$ MSM plus oil paint (final conc. $300 \mathrm{ppm}$, w/v). The percent removal of oil-based paint was determined against a standard curve of oil-based paint prepared by using UV-Vis spectrophotometer at $285 \mathrm{~nm}$ ( $\lambda$ Max.). Three bacterial isolates, Bacillus subtilis strain NAP1 (GenBank: KJ872852), B. subtilis strain NAP2 (GenBank: KJ872853) and B. subtilis strain NAP4 (GenBank: KJ872855) were isolated and identified. All the isolated strains were char-
\end{abstract}

N. A. Kanhar

nisar.kanhar@salu.edu.pk

1 Department of Microbiology, Shah Abdul Latif University, Khairpur (Mir's), Sindh 66020, Pakistan

2 Department of Microbiology, Quaid-i-Azam University, Islamabad 45320, Pakistan acterized as potential oil-based paint degraders. Maximum oil-based paint removal was recorded with strains NAP1 $(66.5 \%)$, followed by NAP2 $(61.4 \%)$ and NAP4 $(55.9 \%)$. The oil-based-paint-polluted environments are a promising source of oil-based-paint-degrading bacteria. The bacterial isolates of present study offer substantial potential for future environmental applications.

Keywords Bacillus species - Biodegradation - Oil-based paints · Pollutants $\cdot$ Soil enrichment technique

\section{Introduction}

Paint is one of the oldest synthetic substances known to mankind, with a history stretching back into pre-historic times (Ravikumar et al. 2012). Paints are stable mechanical mixtures of one or more pigments and various chemical components (Odokuma et al. 2013; Sharma 2006). The paints consist of: (a) binder/additive, which adhere paints to the surface, (b) pigments, which give the paint a color and prevent corrosion, and (c) solvents to make the paint spreadable (Ravikumar et al. 2012). The modern household paints fall into two broad categories, i.e., (1) 'orthodox', the oil-based or solvent-based paints, thinned with mineral turpentine or other organic solvents, and (2) 'emulsion paints', the water-based vinyl or acrylic paints that may be thinned with water (Odokuma et al. 2013).

Contaminated lands resulted from the industrial revolution in the past century, when the awareness of health and environmental effects connected with the release, production, use, and disposal of hazardous substances were less recognized than today (Sethy et al. 2011; Vidali 2001). In some cases, industrial effluent releases are well regulated (e.g., industrial emissions), while in other they are 
accidental (e.g., chemical or oil spills). Most common oilbased spillage pollutants are benzene, toluene, ethylbenzene, and mixture of xylene (BTEX) compounds. Fortunately, such incidents rarely occur, although they can result in significant contaminations of the soil and water environments (Chakraborty and Coates 2004; Pratheesh and Jayachandran 2012). BTEX compounds are classified as major environmental pollutants on the Environmental Protection Agency (EPA) list of priority pollutants with high frequencies of occurrence (Farhadian et al. 2008) which may be lethal and persistent in terrestrial and aquatic environments. The volatile organic compounds (VOCs) like ethylbenze, $n$-hexane, and xylene in the oil-based paints, on the other hand, are considered to be harmful to the environment, especially for the people who work with them on a regular basis (Saitta et al. 2014). The exposure to VOCs has been related to organic solvent syndrome (Spurgeon 2006). According to the International Agency for Research on Cancer (IARC), the painting as an occupation was classified to be carcinogenic to human beings. There is sufficient evidence in humans for the occupational carcinogenicity of lungs and urinary bladder with exposure as a painter (IARC 1990).

There are several soil-cleaning methods to reduce toxicity and hazards of environment, including incineration (burning), washing, chemical applying, land filling, and bioremediation (Azhdarpoor et al. 2014; Martínez et al. 2000). However, these removal or treatment technologies except bioremediation have been found to have inherent drawbacks owing to their tendency to form secondary toxic intermediates and also proven to be costly (Mohsenzadeh et al. 2012). Thus, the major emphasis of the development of technology is related to safe and cost-effective detoxification and degradation of the environmental pollutants. Therefore, biological removal (bioremediation) treatment technology has turned out to be a favorable alternative because it produces no toxic end products and is cost-effective (Mohsenzadeh et al. 2012). Recently, Saitta et al. (2014) reported a potential remediation method for PCBcontaminated paint under laboratory conditions based on non-metallic treatment system (NMTS). The methods like NMTS, in addition to bioremediation, could facilitate complete remediation of the oil-based-paint-contaminated ecosystems through cost-effective and environmentfriendly processes.

The biodegradation and bioremediation of paints is unexplored field of research in the Pakistan and a little explored throughout the world. Environmentalists have recently reported variety of microorganisms isolated from the paints having capability of biodegradation and bioremediation of paints and paint-related wastes (Okunye et al. 2013; Ravikumar et al. 2012; Rosado et al. 2013; Sridevi et al. 2011). The environment contaminated with key pollutants could be an ideal source of the microbes utilizing or degrading them. Data noted from available literature supports the prevalence of efficient pollutant-degrading bacteria in soils polluted with same pollutant and from wastes of pollutant (Soudi and Kolahchi 2011). Banerjee and Ghoshal in 2010 isolated phenol-degrading bacterial strains of Bacillus cereus from similar sites (Banerjee and Ghoshal 2010) such as petroleum refinery and oil exploration sites. Thus, it is experienced that the hazardous pollutant-polluted sites are novel and sources of choice for the isolation of microorganisms carrying out biodegradation and bioremediation. The bacterial degradation of paint is normally faster than the fungi to mineralize the paints through combined metabolic mode of aerobic-anaerobic reaction in the form of consortia (Chang et al. 2004). Consequently, different paint-degrading bacterial species belonging to genera Pseudomonas, Micrococcus, Sphingomonas, Thiobacillus, Mycobacterium, Clostridium, Alcaligenes, Bacillus, Flavobacterium, Arthrobacter, Gallionella, Staphylococcus, Gracilibacillus, Salibacillus, Virgibacillus, and Shewanella, etc. have been characterized (Gorbushina et al. 2004; Ravikumar et al. 2012; Subathra et al. 2013). As the catabolic activities of microorganisms in the form of consortia complement each other, obviously syntrophic interaction present in the mixed communities can lead to complete mineralization of the paints (Chang et al. 2004). The aim of present study was thus to isolate, identify, and to seek the bioremediation potential of the oilbased-paint-degrading bacterial strains from oil-basedpaint-polluted soil of Khairpur and Sukkur cities of Pakistan.

\section{Materials and methods}

\section{Collection of soil samples and their treatment}

Paint-polluted soil samples from seven warehouses (one from each) were collected from Sukkur (Lat: $27^{\circ} 41^{\prime} 38.897^{\prime \prime} \mathrm{N}$; Lon: $68^{\circ} 52^{\prime} 7.258^{\prime \prime} \mathrm{E}$ ) and Khairpur (Lat: $27^{\circ} 31^{\prime} 34.442^{\prime \prime} \mathrm{N}$; Lon: $68^{\circ} 45^{\prime} 31.789^{\prime \prime} \mathrm{E}$ ) cities of Pakistan adapting from Wieser et al. (1999). The aerobic surface material of spilled paints was scraped off to a depth of 3-10 $\mathrm{mm}$ from extensively dried areas showing extensive damage with visible and invisible discoloration. The collected soil samples were processed according to the method of Omar et al. (2013) with slight modification. Briefly, $1 \mathrm{~g}$ of the collected soil sample was dissolved in $50 \mathrm{ml}$ of distilled water in shake flasks $(200 \mathrm{rpm})$ at $37{ }^{\circ} \mathrm{C}$ for 30 min. After settling of the larger soil particles at room temperature for $30 \mathrm{~min}$., approximately $0.1 \mathrm{ml}$ of soil suspension was used as inoculum for the isolation of bacteria. 


\section{Enrichment of soil samples and media conditions}

Mineral salt medium (MSM) was modified from Yonetani et al. (2004) that contained $(\mathrm{g} / \mathrm{l}): \mathrm{MgSO}_{4} \cdot 7 \mathrm{H}_{2} \mathrm{O}, 10$; $\mathrm{CaCl}_{2} \cdot 7 \mathrm{H}_{2} \mathrm{O}, 0.2$; and, $\mathrm{KH}_{2} \mathrm{PO}_{4}, 13.6$; $\left(\mathrm{NH}_{4}\right)_{2} \cdot \mathrm{SO}_{4}, 2.4$; $\mathrm{FeSO}_{4} \cdot 7 \mathrm{H}_{2} \mathrm{O}, 0.2 ; \mathrm{Na}_{2} \mathrm{HPO}_{4} \cdot 12 \mathrm{H}_{2} \mathrm{O}, 15$; and agar, 12 (in case of MSM agar only). All the salt solutions were separately prepared and autoclaved at $121{ }^{\circ} \mathrm{C}, 15 \mathrm{lb}$ pressure for $15 \mathrm{~min}$, and dissolved one by one into the main MSM medium (approximately $980 \mathrm{ml}$ of distilled water). The $\mathrm{pH}$ of the medium was adjusted to $7.0 \pm 0.2$ using $6 \mathrm{~N} \mathrm{HCl}$ and $1 \mathrm{M} \mathrm{NaOH}$ solutions. The soil suspension $(0.1 \%$, v/v) was aseptically added to the $250-\mathrm{ml}$ shake flasks containing $100 \mathrm{ml}$ of MSM broth enriched with oil paint (ALBA synthetic enamel, white-32) at a final concentration of 100 , 200, and $300 \mathrm{ppm}$ as a sole source of carbon and incubated at $37{ }^{\circ} \mathrm{C}$ and $160 \mathrm{rpm}$ for 14 days in the Multi-tier environmental shaker (Innova ${ }^{\circledR}$, Germany). The growth absorbance $\left(\mathrm{O} \mathrm{D}_{600 \mathrm{~nm}}\right)$ of each sample was regularly measured after 1-day interval using spectrophotometer (Jennway, Germany).

\section{Isolation and screening of oil-based-paint-utilizing bacteria}

Based on the growth absorbance $\left(\mathrm{O}_{\mathrm{D}} \mathrm{D}_{600 \mathrm{~nm}}\right)$, the samples showing maximum growth absorbance were selected and streaked onto the surface of MSM agar plates enriched with (w/v) oil-based paint (final conc. 300 ppm). The MSM agar contained the same composition of salts as mentioned above in previous subsection of this manuscript and agar at a concentration of $1.2 \%(\mathrm{w} / \mathrm{v})$ as solidifying agent. Afterward, the bacterial colonies were picked off from the plates and purified by repetitive streaking onto nutrient agar plates.

\section{Identification of bacterial isolates}

After cultural characteristics (Heyrman et al. 1999; Saadoun 2002), the bacterial isolates were studied for morphological characterization. The tests including Gram's staining, motility test, spore staining, and capsule staining were performed for the morphological characterization. Finally, the bacterial isolates, as pure cultures, were grown in nutrient broth and further investigated for their biochemical characteristics. The nutrient agar and nutrient broth media were purchased from oxoid ${ }^{\circledR}$ (Oxoid, UK).

\section{Molecular identification using 16S rRNA}

The molecular identification of the selected bacterial isolates was commercially carried out by partial sequencing of the 16S rRNA gene at the Genomic Division, Macrogen
Inc., Seoul, Korea. The molecular identification of the isolates was performed by amplification using universal primers, 27F ( $5^{\prime}$-AGAGTTTGATCMTGGCTCAG- $\left.{ }^{\prime}\right)$ and 1492R (5'-TACGGYTACCTTGTTACGACTT- $\left.{ }^{\prime}\right)$. The amplified gene products were then purified and sequences were obtained through ABI PRISM Big Dye ${ }^{\mathrm{TM}}$ Terminator Cycle Sequencing Ready Reaction Kit (PE Biosystem, USA) by using universal sequencing primers, i.e., $518 \mathrm{~F}\left(5^{\prime}\right.$ CCAGCAGCCGCGGTAATACG-3') and 800R (5'-TACCAGGGTATCTAATCC-3').

\section{Phylogenetic correlation analysis}

The partial sequence of the 16S rRNA gene obtained in this study was analyzed and compared with nucleotide sequence databases in the National Center for Biotechnology Information (NCBI) website using Basic Local Alignment Search Tool (BLAST) program, in order to confer the percentage sequence similarities. The evolutionary history was inferred by using the Maximum Likelihood Method based on the Tamura-Nei model (1993). Evolutionary analyses were conducted in MEGA6 according to the (Tamura et al. 2004, 2013). The nucleotide sequences of all the isolates were submitted to GenBank NCBI for the accession numbers.

\section{Bioremediation of oil-based paint}

All the bacterial strains of $B$. subtilis (i.e., NAP1, NAP2 and NAP4) were grown in nutrient broth for $18-20 \mathrm{~h}$ at $37^{\circ} \mathrm{C}$. Afterward, samples were centrifuged $(4000 \mathrm{rpm}$, $10 \mathrm{~min}$ ) and cells were collected. The pellets were then washed thrice with sterile saline $(0.9 \% \mathrm{NaCl}, \mathrm{w} / \mathrm{v})$ and centrifuged again (4000 rpm, $5 \mathrm{~min}$ ), in order to remove excess media components. The cells were re-suspended in MSM and used as inocula for all the biodegradation experiments. Briefly, the MSM broth supplemented with oil-based paint at a final concentration of $300 \mathrm{ppm}(\mathrm{w} / \mathrm{v})$ was separately inoculated with $B$. subtilis isolates NAP1, NAP2, and NAP4 for the bioremediation of oil-based paint. The experiment was done under aerobic condition in environmental shaking incubator (Innova 4900, Germany) with $160 \mathrm{rpm}$, at $37{ }^{\circ} \mathrm{C}$ for 14 days. Negative control was run without inocula of respective isolate and without carbon source (oil paint) in the similar conditions. The growth absorbance of selected bacterial strains was recorded after every 2 nd day of incubation including 0 days.

\section{Analytical methods}

Paint standard at different conc. (i.e., 100, 200, 300, and $400 \mathrm{ppm}$ ) was dissolved in petroleum ether and its absorbance was recorded at $285 \mathrm{~nm}$ against a blank of petroleum 
Fig. 1 Growth absorbance of soil samples enriched in MSM (100, 200 and $300 \mathrm{ppm})$. The experiments were performed in 250-ml shake flasks containing $100 \mathrm{ml}$ of enriched MSM broth containing: KSSA Khairpur soil sample A, KSSB Khairpur soil sample B, KSSC Khairpur soil sample C, KSSD Khairpur soil sample D, SSSA Sukkur soil sample A, SSSB Sukkur soil sample B, SSSC Sukkur soil sample C broth with (v/v) oil-based paint
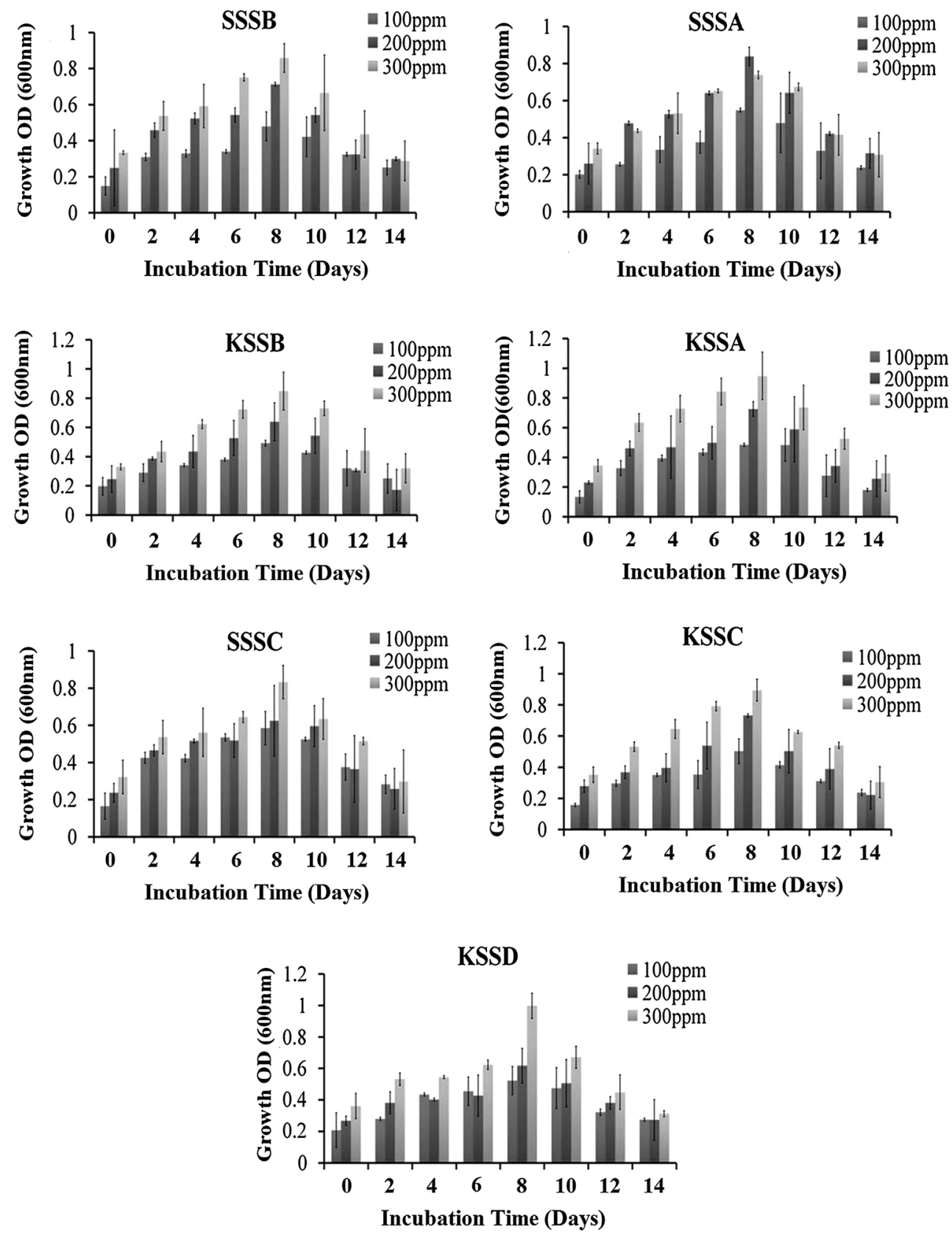

ether by using UV-Vis spectrophotometer (Agilent 8453, USA). The absorbance of the treated samples was then plotted against oil-based paint concentration. The linear regression value $\left(R^{2}\right)$ was calculated using Microsoft Excel (Version 2007) in order to quantify the oil-based paint concentration in unknown test samples of the biodegradation experiments.

\section{Fourier transform infrared (FTIR) spectrometry}

The oil-based paint biodegradation was evaluated by using spectrometric analysis using Tensor 27 bench-top FTIR spectrometer (Brüker, Germany) equipped with universal diamond attenuated total reflectance (ATR) accessory (Pike Miracle, USA). The cell-free supernatants of the biodegradation experiments were obtained at 0 and 14 days of incubation and interpreted for changes after treatment in the percent transmittance of specific peaks related to that of oil-based paint before treatment. The cell-free supernatant (CFS) sample (approximately $100 \mu \mathrm{l}$ ) was placed over the diamond ATR probe, and the spectra were recorded (wave number range $600-4000 \mathrm{~cm}^{-1}$ ) at the rate of 16 scans per scanning. 
Fig. 2 Screening and selection of oil-based-paint-degrading bacteria. The flask showing best growth O.Ds was streaked on the surface of MSM agar plates supplemented with oil-based paint (300 ppm, w/v) as sole source of carbon and energy. The bacterial isolates utilizing oilbased paint as sole source of carbon and showing potential growth were then sub-cultured on nutrient agar for further cultural, morphological and biochemical characterization. NAP1 was isolated from SSSA soil sample from MSM enrichment medium containing oil-based paint at a concentration of $200 \mathrm{ppm}(\mathrm{w} / \mathrm{v})$, while NAP2 and NAP4 were isolated from soil samples of Khairpur (KSSC and KSSD), using enriched mineral salts media containing oil-based paint at a concentration of $300 \mathrm{ppm}(\mathrm{w} /$ v)

Table 1 Preliminary identification of bacterial isolate by routine microbiological methods

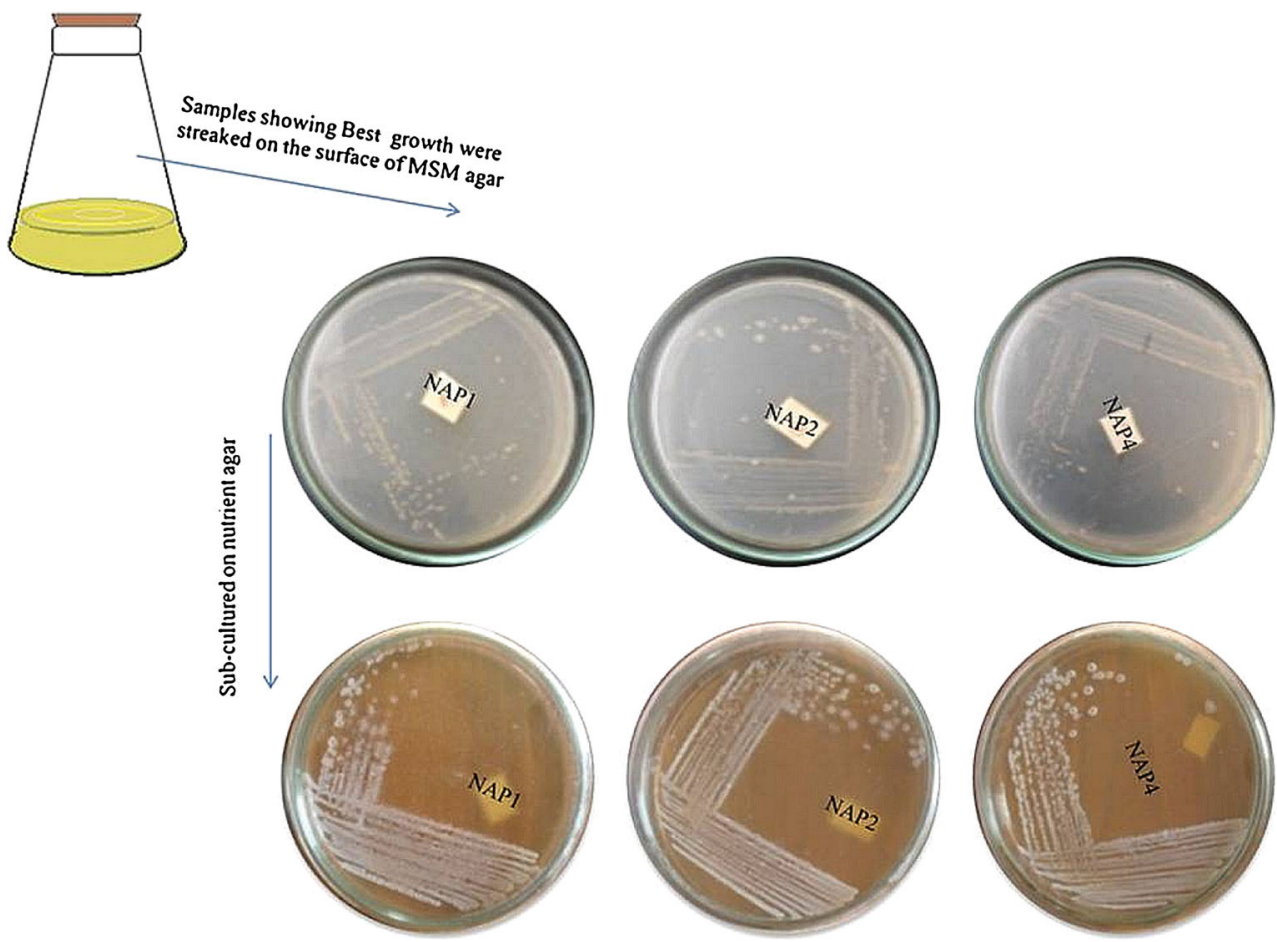

\begin{tabular}{|c|c|c|c|}
\hline \multirow[t]{2}{*}{ Characteristics } & \multicolumn{3}{|l|}{ Bacterial isolates } \\
\hline & NAP1 & NAP2 & NAP4 \\
\hline Colonial characteristics & Circular, white & Circular, white & Circular, white \\
\hline \multicolumn{4}{|l|}{ Morphological } \\
\hline Gram's reaction & + & + & + \\
\hline Shape & Bacilli & Bacilli & Bacilli \\
\hline Capsule staining & + & + & + \\
\hline Spore staining & + & + & + \\
\hline Motility test & + & + & + \\
\hline \multicolumn{4}{|l|}{ Biochemical } \\
\hline Indole & - & - & - \\
\hline Methyl red & - & - & - \\
\hline Voges-Proskauer & - & - & - \\
\hline Citrate utilization & + & + & + \\
\hline Catalase & + & + & + \\
\hline Oxidase & + & + & + \\
\hline Nitrate reduction & + & + & + \\
\hline Urease test & - & - & - \\
\hline Glucose fermentation & + & + & + \\
\hline Lactose fermentation & + & + & + \\
\hline Maltose fermentation & - & - & - \\
\hline Sucrose fermentation & + & + & + \\
\hline
\end{tabular}




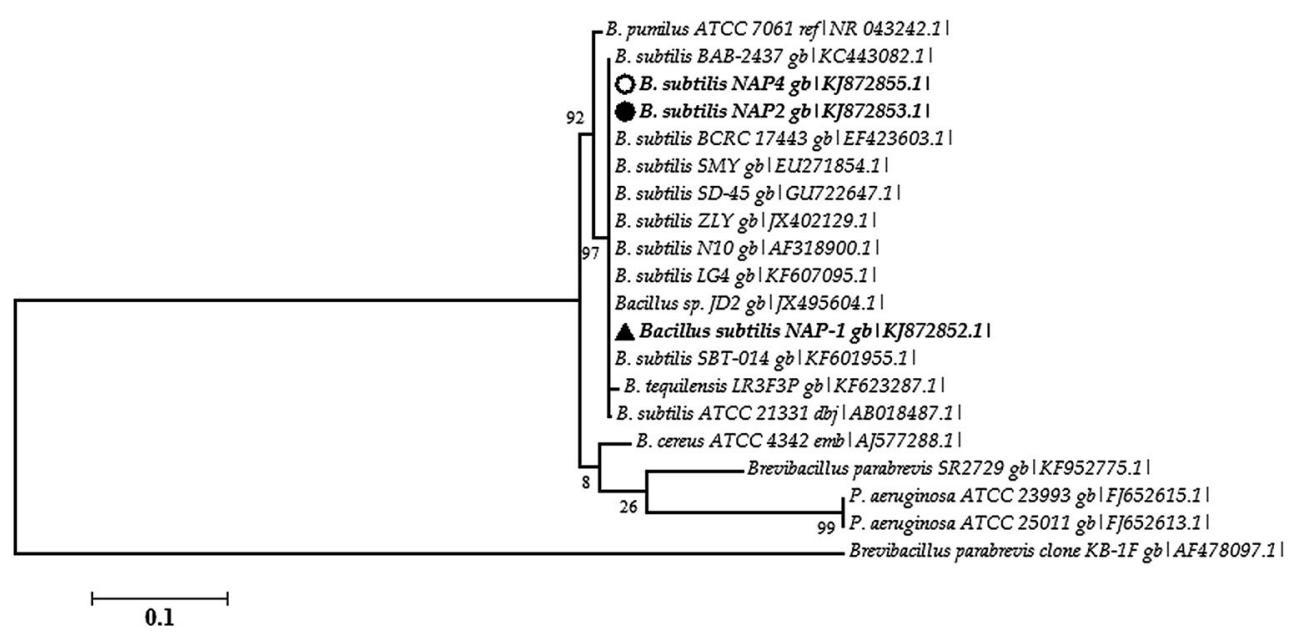

Fig. 3 Neighbor-joining (NJ) tree of oil-based-paint-degrading Bacillus sp. isolates. The evolutionary history was inferred by using the maximum likelihood method based on the Tamura-Nei model (1993). The percentage of trees in which the associated taxa clustered together is shown next to the branches. Initial tree(s) for the heuristic

\section{Results and discussion}

To isolate bacteria with desired metabolic activity directly from the natural environment is rarely feasible (Marchesi and Weightman 2003). To make the best isolation of bacterial species with special abilities from sites of pollution, enrichment method, is still an all-important process particularly where the target pollutants serve as the carbon and energy source (Nwinyi 2011; Soudi and Kolahchi 2011). Therefore, soil enrichment technique was used to process the collected soil samples under laboratory conditions. All the collected samples were thus processed for the isolation of bacteria by using soil enrichment technique under shake flask conditions. Another possible method for increasing the microbial tolerance during substrate inhibition is to complement the growth medium with conventional carbon sources (augmentation), such as yeast extract or glucose. It has also been noted that the presence of glucose enhanced the affinity of bacterial isolates for substrate (source of carbon; Bhattacharya et al. 2012). The samples were enriched at 100-300 ppm concentration of oil-based paint as a source of carbon and energy in MSM broth, to isolate the screened bacterial strains having desired metabolic capabilities. The quantitative effect of substrate inhibition (oil-based paint) on the biomass showed that up to $300 \mathrm{ppm}$, biomass of bacteria was sufficient and any further increase in the substrate concentration resulted in further decrease in biomass. Therefore, $300 \mathrm{ppm}$ concentration of oil-based paint was selected as the optimum concentration for the screening and biodegradation and bioremediation by using of oil-basedpaint-degrading bacteria. search were obtained automatically by applying Neighbor-Join and BioNJ algorithms to a matrix of pairwise distances estimated using the maximum composite likelihood (MCL) approach, and the evolutionary analyses were conducted in MEGA6 according to the Tamura et al. (2013)

The growth of microorganisms in organic pollutants is often indicated by an increase in turbidity and decrease in pH (Nwinyi 2011). The decrease in the biomass may be due to the formation of degraded substrate into toxic metabolites (Vidhya and Thatheyus 2013). Thus, the growth of all the samples was observed through increasing the turbidity of the culture medium without yeast extract or glucose. Maximum growth was recorded in Sukkur soil sample A (SSSA) at $200 \mathrm{ppm}$ concentration followed by Khairpur soil sample A (KSSA), Khairpur soil sample C (KSSC), and Khairpur soil sample D (KSSD) at $300 \mathrm{ppm}$ oil-based paint concentration. The optimal growth on the 8th day of incubation correlated slow start of microbial degradation (Mirizadeh et al. 2014) and might have required an acclimatization period before rapid degradation (Fig. 1). Based on the growth ODs taken with 100-300 ppm oil-paint, three of the soil samples showing best growth ODs, i.e., SSSA, KSSA, and KSSD, were further streaked on the surface of MSM agar plates containing oil-paint (300 ppm, w/v) as sole source of carbon and energy for isolation of cultivable predominant bacteria. The inoculated MSM plates showed visible bacterial growth during 4 days of incubation, and three of the bacterial isolates, viz. NAP1, NAP2, and NAP4 were isolated as pure cultures (Fig. 2).

The pure bacterial isolates were then identified by using cultural, morphological, and by biochemical characterization methods as shown in Table 1. The isolates were Gram's positive bacilli, spore and capsule forming, motile, fermented sugars (Glucose, lactose and sucrose), Indole, Methyl red, Voges-Proskauer negative where as the catalase, oxidase, nitrate reduction and citrate utilization were 
Fig. 4 Bacterial growth and \% oil-based paint removal by oilbased-paint-degrading bacteria. The growth solid line with triangle and \%oil-based paint removal solid line with open circle was monitored in MSM supplemented with or without glucose in addition to oil-based paint (at a conc. $300 \mathrm{ppm}$, w/v) for a period of 14 days. a, c, e demonstrate the experimental runs without glucose supplementation, while the $\mathbf{b}, \mathbf{d}$, f represent the growth and oilbased paint biodegradation rates obtained with glucose supplementation into MSM by Bacillus isolates NAP1, NAP2, and NAP4, respectively. The samples were drawn after every 2 days. The value represented here are mean of triplicate experiments, whereas the error bars indicate standard deviation among the replicate experiments

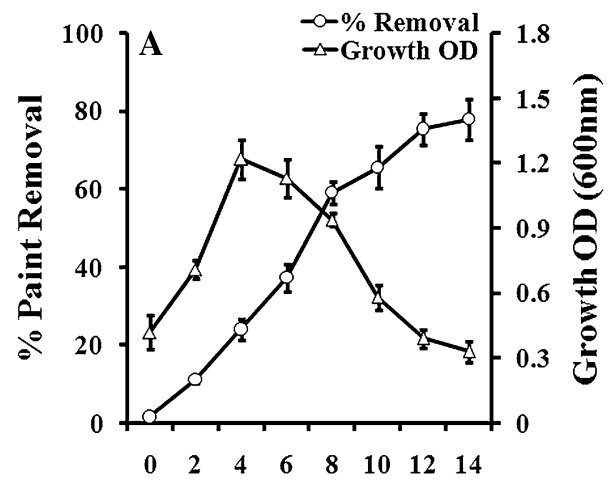

Incubation Time (Days)

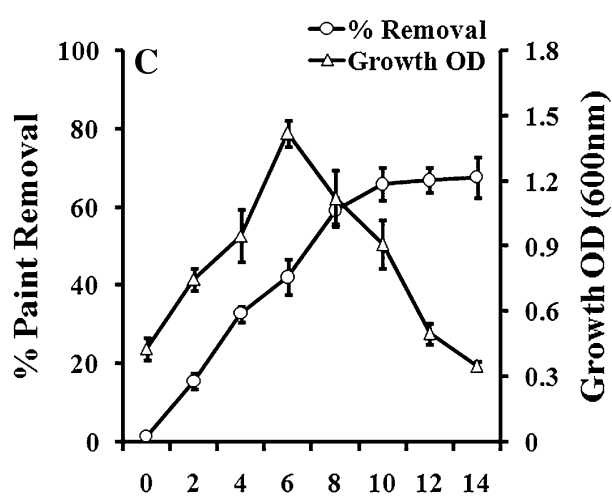

Incubation Time (Days)

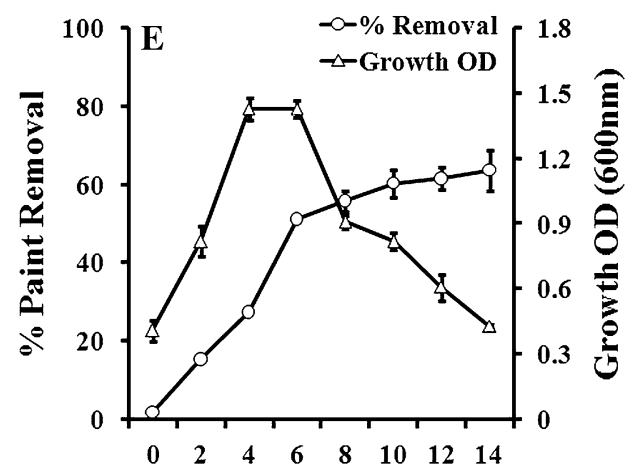

Incubation Time (Days)

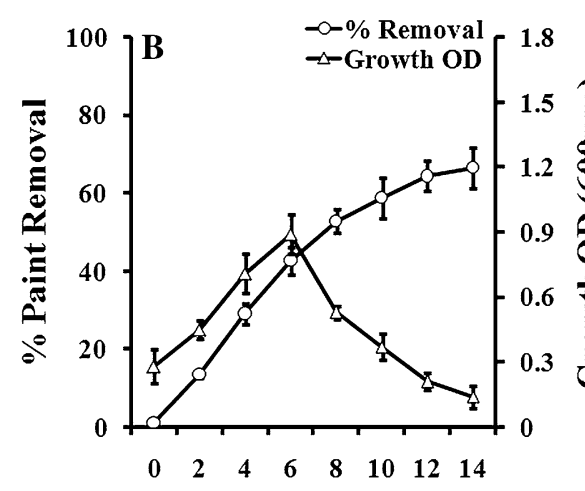

Incubation Time (Days)

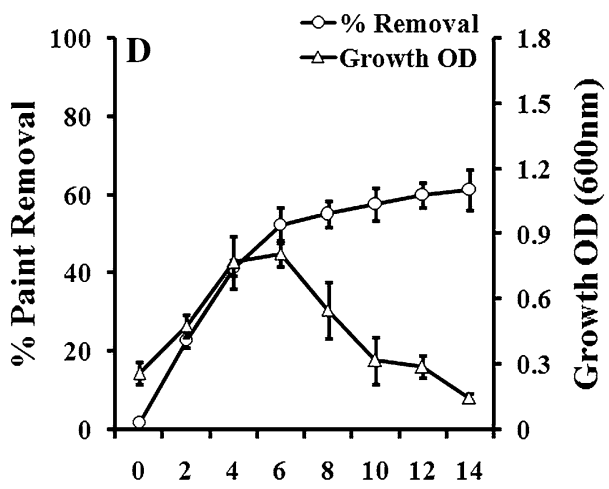

Incubation Time (Days)

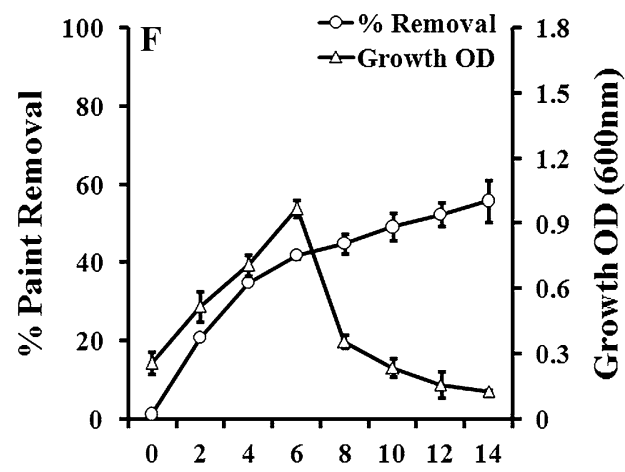

Incubation Time (Days) positive as shown in Table 1 . The preliminary results of bacterial isolate (NAP1, NAP2, and NAP4) identification by traditional methods showed that all species belong to Bacillus genera. However, to date, different genera belonging to Pseudomonas, Micrococcus, Sphingomonas, Thiobacillus, Mycobacterium, Clostridium, Alcaligenes, Bacillus, Flavobacterium, Arthrobacter, Gallionella, and Shewanella have been characterized and reported in the literature as paint and painted surface-degrading strains (Gorbushina et al. 2004; Ravikumar et al. 2012). Concurrently, Bacillus species were also predominant among other bacterial species that have been most frequently isolated in several studies (Odokuma et al. 2013).

To further confirm the identity, the molecular characterization was carried out using $16 \mathrm{~S}$ rRNA sequence homology. Based on molecular characterization, all the three isolates showed more than $99 \%$ similarity with Bacillus subtilis isolates available in NCBI GenBank library. Thus, the isolates were confirmed as the strains of B. subtilis as shown in Fig. 3. The nucleotide sequences of each isolate was submitted to NCBI GenBank, USA, and accession numbers KJ872852, KJ872853, KJ872855 were 
Table 2 Characteristic IR transmittance frequencies of organic functional groups of oilbased paints

\begin{tabular}{|c|c|c|c|c|}
\hline \multirow[t]{2}{*}{ Band frequency $\left(\mathrm{cm}^{-1}\right)$} & \multirow[t]{2}{*}{ Assignment } & \multicolumn{3}{|c|}{ Bacterial isolates \& } \\
\hline & & NAP1 & NAP2 & NAP4 \\
\hline $1100-1250$ & $\mathrm{C}-\mathrm{O}-\mathrm{C}$ (ester) stretching & & $x$ & $\times$ \\
\hline $1300-1500$ & $\mathrm{CH} 3$ asymmetric bending & $x$ & & $\times$ \\
\hline $1500-1660$ & $\mathrm{NO}_{2}$ bond & & & \\
\hline $1650-1750$ & $\mathrm{C}=\mathrm{C}$ (acid/ester) stretching & $x$ & $x$ & $x$ \\
\hline $2850-2960$ & $v \mathrm{SCH}_{2} / \mathrm{CH}_{3}$ stretch & $\times$ & $\times$ & $\times$ \\
\hline $3000-2500$ & $-\mathrm{OOH}$ bond & & & $x$ \\
\hline $3000-3100$ & $\mathrm{C}-\mathrm{H}$ stretch (aromatic rings) & & $\times$ & $x$ \\
\hline $3200-3600$ & $\mathrm{OH} / \mathrm{NH}_{2}$ stretching (alcohols, phenols, amides) & $\times$ & $x$ & $x$ \\
\hline
\end{tabular}

received against all the submitted nucleotide sequences, i.e., B. subtilis strain NAP1, B. subtilis strain NAP2 and B. subtilis strain NAP4, respectively.

However, the microbial activities allow mineralization of some of the recalcitrant pollutants into carbon dioxide and water. Although, the microbial transformation is considered a major route for complete degradation of such components (Bhattacharya et al. 2012). In present study, all the three Bacillus strains, viz. NAP1, NAP2, and NAP4 were used for the biodegradation of oil-based paint, and their $\%$ oil-based-paint-removal efficiencies were determined (Fig. 4). Maximum oil-based paint removal was achieved with $B$. subtilis strain NAP1 (77.9 and $66.5 \%$ ) followed by B. subtilis strain NAP2 (67.4 and 61.4\%), and B. subtilis strain NAP4 (63.6 and $55.9 \%)$ with and without glucose addition, respectively (Fig. 4). In addition, the biodegradation efficiencies were significantly higher with glucose as an additional carbon source, in case of all the three Bacillus isolates. The potency of microbes as agents for degradation of several compounds thus indicates that biological treatment can be a promising alternative to attenuate environmental impact caused by pollutants (Bhattacharya et al. 2012; Odokuma et al. 2013). Similarly, Odokuma et al. (2013) also reported that Bacillus sp. and Pseudomonas sp. exhibited higher predominance on painted surfaces, paint and paint waste that may be attributed to different survival strategies evolved by these microorganisms. Some of the strategies include exposure to higher concentrations of the pollutants (e.g., oil-based paint), so that the bacterial isolates can withstand elevated concentrations of the pollutant and get acclimatized to use that pollutant as sole source of carbon and energy. It has also been noted that the presence of glucose enhanced the affinity of bacterial isolates for oil-based paint (Bhattacharya et al. 2012). Consequently, the biodegradation efficiencies were significantly higher with glucose as an additional carbon source, in case of all the three Bacillus isolates.

The FTIR spectra of cell-free supernatants of $B$. $s u b$ tilis strains NAP1, NAP2, and NAP4 revealed major changes in the oil-based-paint-relevant peaks at wave number range of 800-600, 1034-1299, 1690-1725, 2857-3000, and $3200-3400 \mathrm{~cm}^{-1}$ in treated samples as compared to the samples before biodegradation (Table 2; Fig. 5). The prominent changes in the peaks at wavelength $1034-1299$ and $2857-3000 \mathrm{~cm}^{-1}$ correspond to the biodegradation of aromatic compounds like BTEX compounds and aliphatic chains of oils used in oil-based paints (such as linoleic acid etc.), respectively. Similarly, changes in the \% transmittance of ketone bonds in the wave number range of $1690-1725 \mathrm{~cm}^{-1}$ further confirmed saturation and hydroxylation of the aliphatic and aromatic hydrocarbon components of the oil-based paints. It was proposed that the major changes in the FTIR spectra of oil-based paint designated the attachment/breakdown of the backbone polymer present in the oil-based paint, which in turn correspond to its hydroxylation and oxidation leading to the biodegradation of oil-based paint by Bacillus species. However, the current work is only a step forward to the understanding about oil-based paint biodegradation and needs some more elaborated studies to exploit the complete mechanisms and pathways involved in the microbial degradation of oil-based paints. However, the FTIR spectra showing broadbands in the frequency range of $3200-3400 \mathrm{~cm}^{-1}$ also indicated $\mathrm{NH}_{2}$ stretch of the extracellular enzymes like peroxidases and dehydrogenases produced by Bacillus species during biodegradation of hydrocarbon pollutants (the enzyme assay results not shown). The peaks in the wave number range of $800-600 \mathrm{~cm}^{-1}$ could be correlated to the $\mathrm{C}-\mathrm{C}$ and $\mathrm{C}-\mathrm{H}$ interactions of straight chain aliphatics.

\section{Conclusion}

It was concluded that the isolated Bacillus species were more resistant to oil-based paints or had different strategies to tolerate elevated oil-based paint concentrations. This could be one of the reasons why Bacillus species 

the cell-free supernatants before and after treatment indicating oil-based paint degradation. The $\%$ transmittance overlay spectra taken at 0 and 14 day (i.e., before and after treatment) are shown. The lines labeled as 0 and 14 represent the biodegradation experiments performed without glucose addition, whereas the lines labeled as G-0 and G-14 represent the experiments performed with glucose in addition to oil-based paint as carbon and energy source
Fig. 5 Overlay FTIR spectra of
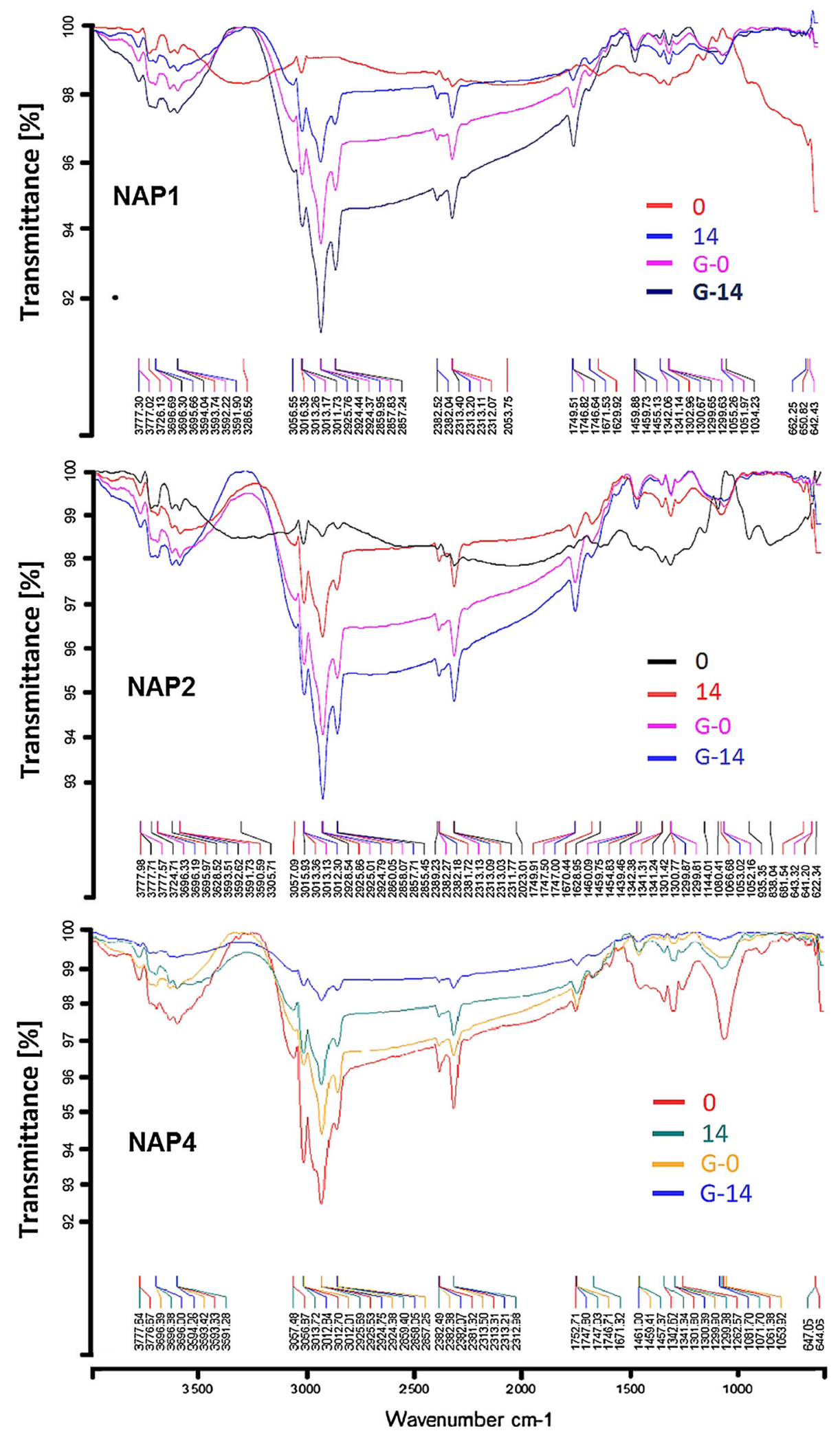

predominate other bacterial species inhabiting the oilbased-paint-polluted environment. The isolated $B$. subtilis utilized the oil-based paints as sole source of carbon and energy and rendered them non-toxic at the experimental conditions. It was also concluded that isolates of the present study have strong potential for oil-based paint biodegradation and can be used in the bioremediation of oil-based-paint-polluted ecosystems. 
Acknowledgments We are highly thankful to Dr. Fariha Hassan, Chairperson Department of Microbiology, Quaid-i-Azam University, Islamabad, Pakistan, for providing complete access to laboratory equipments and assigning research students for technical guidance for determining the \% removal and FTIR analysis of oil-based paints in samples before and after treatment during biodegradation experiments.

\section{References}

Azhdarpoor A, Mortazavi B, Moussavi G (2014) Oily wastewaters treatment using Pseudomonas sp. isolated from the compost fertilizer. J Environ Health Sci Eng 12:77

Banerjee A, Ghoshal AK (2010) Isolation and characterization of hyper phenol tolerant Bacillus sp. from oil refinery and exploration sites. J Hazard Mater 176:85-91

Bhattacharya S, Das A, Nalini P (2012) Ex situ biodegradation of phenol by native bacterial flora isolated from industrial effluent. J Chem Biol Phys Sci 2:1091-1101

Chakraborty R, Coates JD (2004) Anaerobic degradation of monoaromatic hydrocarbons. Appl Microbiol Biotechnol 64:437-446

Chang J-S, Chen B-Y, Lin YS (2004) Stimulation of bacterial decolorization of an azo dye by extracellular metabolites from Escherichia coli strain NO3. Bioresour Technol 91:243-248. doi:10.1016/S0960-8524(03)00196-2

Farhadian M, Duchez D, Vachelard C, Larroche C (2008) Monoaromatics removal from polluted water through bioreactors-a review. Water Res 42:1325-1341. doi:10.1016/j.watres.2007.10. 021

Gorbushina AA et al (2004) Bacterial and fungal diversity and biodeterioration problems in mural painting environments of St. Martins church (Greene-Kreiensen, Germany). Int Biodeterior Biodegrad 53:13-24. doi:10.1016/j.ibiod.2003.07.003

Heyrman J, Mergaert J, Denys R, Swings J (1999) The use of fatty acid methyl ester analysis (FAME) for the identification of heterotrophic bacteria present on three mural paintings showing severe damage by microorganisms. FEMS Microbiol Lett $181: 55-62$

IARC (1990) Some organic solvents, resin monomers and related compounds, pigments and occupational exposures in paint manufacture and painting. IARC Monogr Eval Carcinog Risk Hum 47:1-442

Marchesi JR, Weightman AJ (2003) Comparing the dehalogenase gene pool in cultivated $\alpha$-halocarboxylic acid-degrading bacteria with the environmental metagene pool. Appl Environ Microbiol 69:4375-4382

Martínez MG, Santos AG, Cruz LG, de Oca García MM, Trujillo LY, Lis JZE, Gutiérrez-Rojas M (2000) Diagnostic and resulting approaches to restore petroleum-contaminated soil in a Mexican tropical swamp. Water Sci Technol 42:377-384

Mirizadeh S, Yaghmaei S, Nejad ZG (2014) Biodegradation of cyanide by a new isolated strain under alkaline conditions and optimization by response surface methodology (RSM). J Environ Health Sci Eng 12:85

Mohsenzadeh F, Rad AC, Akbari M (2012) Evaluation of oil removal efficiency and enzymatic activity in some fungal strains for bioremediation of petroleum-polluted soils. Iran $\mathrm{J}$ Environ Health Sci Eng 9:1-8

Nwinyi O (2011) Enrichment and identification of Askarel oil (PCB blend) degrading bacteria enriched from landfill sites in Edo State, Nigeria. Agric Biol J N Am 2:89-100

Odokuma LO, Berebon DP, Ogbonna CB (2013) Potential biodeteriogens of indoor and outdoor surfaces (coated with gloss, emulsion and textcoat paints). IOSR J Pharmacol Biol Sci (IOSR-JPBS) 7:12-19

Okunye OL, Morakinyo KO, Ayedun JS (2013) Isolation and characterization of fungi associated with in-can degradation of paint. J Environ Earth Sci 3:142-145

Omar OC, Kirsteen OP, David MO, Anthony S, Annette OW (2013) Molecular clustering of microbial flora and bacterial degradation of textile dyes by isolates from contaminated soils. Elixir Bio Tech 54:12452-12459

Pratheesh PT, Jayachandran K (2012) Biodegradation of toluene hydrocarbon by a Pseudomonas sp. isolated from gasoline contaminated soil. Int J Plant Anim Env Sci 2:210-216

Ravikumar HR, Rao SS, Karigar CS (2012) Biodegradation of paints: a current status. Indian J Sci Technol 5:1977-1987

Rosado T, Martins MR, Pires M, Mirão J, Candeias A, Caldeira AT (2013) Enzymatic monitorization of mural paintings biodegradation and biodeterioration. Int J Conserv Sci 4:603-612

Saadoun I (2002) Isolation and characterization of bacteria from crude petroleum oil contaminated soil and their potential to degrade diesel fuel. J Basic Microbiol 42:420-428

Saitta EKH, Gittings MJ, Clausen C, Quinn J, Yestrebsky CL (2014) Laboratory evaluation of a prospective remediation method for PCB-contaminated paint. J Environ Health Sci Eng 12:57

Sethy NK, Jha VN, Sahoo SK, Shukla AK, Tripathi RM, Puranik VD (2011) Ground water ingestion dose due to intake of radionuclide (Natural $\mathrm{U}$ and ${ }^{226} \mathrm{Ra}$ ) to population around Uranium mining complex at Jaduguda. J Ecosyst Ecogr 1:104. doi:10.4172/21577625.1000104

Sharma BK (2006) Industrial chemistry (including chemical engineering), 15th edn. GOED, Meerut

Soudi MR, Kolahchi N (2011) Bioremediation potential of a phenol degrading bacterium, Rhodococcus erythropolis SKO-1. Prog Biol Sci 1:31-70

Spurgeon A (2006) Watching paint dry: organic solvent syndrome in late-twentieth-century Britain. Med Hist 50:167-188

Sridevi V, Lakshmi MVVC, Swamy AVN, Rao MN (2011) Implementation of response surface methodology for phenol degradation using Pseudomonas putida (NCIM 2102). J Bioremed Biodeg 2:121. doi:10.4172/2155-6199.1000121

Subathra MK, Immanuel G, Suresh AH (2013) Isolation and Identification of hydrocarbon degrading bacteria from Ennore creek. Bioinformation 9:150-157

Tamura K, Nei M (1993) Estimation of the number of nucleotide substitutions in the control region of mitochondrial DNA in humans and chimpanzees. Mol Biol Evol 10:512-526

Tamura K, Nei M, Kumar S (2004) Prospects for inferring very large phylogenies by using the neighbor-joining method. Proc Natl Acad Sci USA 101:11030-11035

Tamura K, Stecher G, Peterson D, Filipski A, Kumar S (2013) MEGA6: molecular evolutionary genetics analysis version 6.0. Mol Biol Evol 30:2725-2729

Vidali M (2001) Bioremediation. An overview. Pure Appl Chem 73:1163-1172

Vidhya R, Thatheyus AJ (2013) Biodegradation of dimethylformamide using Bacillus subtilis. Am J Microbiol Res 1:10-15. doi:10.12691/ajmr-1-1-3

Wieser M, Schumann P, Martin K, Altenburger P, Burghardt J, Lubitz W, Busse H-J (1999) Agrococcus citreus sp. nov., isolated from a medieval wall painting of the chapel of Castle Herberstein (Austria). Int J Syst Bacteriol 49:1165-1170

Yonetani $\mathrm{R}$ et al (2004) Isolation and characterization of a 1,3dichloro-2-propanol-degrading bacterium. J Health Sci 50:605-612 